\title{
MIGRAÇÃO E USOS SOCIAIS DO FACEBOOK: UMA APROXIMAÇÃO À WEBDIÁSPORA SENEGALESA NO RIO GRANDE DO SUL
}

\author{
Liliane Dutra Brignol ${ }^{1}$ \\ Nathália Drey Costa ${ }^{2}$
}

O artigo parte de uma discussão sobre as relações entre comunicação em rede e migrações transnacionais e da proposição do conceito de webdiáspora para, em um segundo momento, apresentar uma análise exploratória de quatro páginas na rede social online Facebook mantidas por migrantes senegaleses no Rio Grande do Sul, Brasil. Neste texto, as páginas no Facebook são entendidas enquanto parte importante da dinâmica migratória, como ambientes comunicacionais de experimentação e de afirmação identitária, assim como lugar de encontro de uma diáspora que se organiza em termos de associações que disputam políticas de posição e reconhecimento no Brasil. A reflexão integra projeto de pesquisa na área da comunicação sobre as dinâmicas de comunicação em rede e usos das TICs em novos fluxos de migratórios para o estado, especialmente o caso dos migrantes do Senegal em cidades gaúchas.

Palavras-chave: comunicação em rede, migração, webdiáspora, Senegal, Facebook.

Migrações, meios de comunicação e processos comunicacionais configuram-se como um grande tema de pesquisas composto por muitos entrelaçamentos possíveis. Alguns desses vêm sendo desenvolvidos no contexto do grupo de pesquisa "Comunicação em rede, identidades e cidadania", do Departamento de Ciências da Comunicação da Universidade Federal de Santa Maria (UFSM). Trata-se do estudo de usos sociais da internet relacionados à condição migrante e suas implicações para o processo de vivências identitárias e participação cidadã.

\footnotetext{
1 Departamento de Ciências da Comunicação da Universidade Federal de Santa Maria - UFSM. Santa Maria, RS, Brasil.

2 Universidade Federal de Santa Maria - UFSM. Santa Maria, RS, Brasil.
} 
Neste artigo, propomos apresentar o resultado de uma análise exploratória de quatro páginas no Facebook de associações e grupos de migrantes senegaleses no Rio Grande do Sul. O trabalho insere-se no projeto de pesquisa "Comunicação em rede, diferença e interculturalidade em redes sociais de migrantes senegaleses no Rio Grande do Sul: um estudo de práticas e processos comunicacionais em novos fluxos de migrações transnacionais para o Estado" ${ }^{\prime \prime}$, cujo objetivo é entender as dinâmicas de comunicação em rede e as lógicas de redes sociais articuladas pelos migrantes senegaleses em cidades gaúchas, a partir da análise de suas práticas e processos comunicacionais construídos entre usos sociais das mídias e processos de comunicação interpessoal e intercultural.

Além da observação online, o percurso metodológico do projeto constitui-se de entrevistas e conversas informais com sujeitos migrantes, observação participante em atividades promovidas pelos coletivos estudados ${ }^{4}$, além de mapeamento e análise da cobertura midiática sobre a presença da migração senegalesa no Rio Grande do Sul. Através da localização e observação de ambientes comunicacionais na internet produzidos ou apropriados por migrantes senegaleses, foco deste trabalho, é possível conhecer organizações e associações migrantes, entidades de apoio ao fenômeno migratório, assim como entrar em contato com uma rede migratória constituída de sujeitos com experiências plurais, de modo a conhecer com mais profundidade suas lógicas de organização nos contextos migratórios.

O fenômeno da migração senegalesa no Rio Grande do Sul tem despertado a atenção devido ao crescente fluxo de migrantes desta nacionalidade em solo gaúcho. Os dados do fenômeno migratório em direção ao Brasil são relevantes: de acordo com informações divulgadas pela Agência EFE (através de dados disponibilizados pela Polícia Federal), de 2000 a 2012, o número de migrantes africanos no país aumentou em 30 vezes. Segundo relatório da Agência da ONU para Refugiados (Acnur)5 , até outubro de 2014, 2.164 solicitações de refúgio de cidadãos senegaleses estavam sendo processadas.

No contexto local, de acordo com dados do Centro de Acolhimento ao Migrante (CAM), instituição mantida pela Congregação Scalabriniana da Igreja Católica em Caxias do Sul, município da região norte do RS que concentra forte presença migratória, de 2010 a 2014, foram cadastrados 1856 senegaleses na

3 Projeto de pesquisa desenvolvido com apoio da Fundação de Amparo à Pesquisa do Estado do Rio Grande do Sul - Edital FAPERGS n. 02/2014, Programa Pesquisador Gaúcho - PqG.

4 Quanto à observação, conversas informais e entrevistas, são feitas no contexto das cidades com presença do coletivo migratório, sobretudo Caxias do Sul e Porto Alegre, até o momento, e em atividades promovidas pelos próprios coletivos migrantes, como em reunião da Associação dos Senegaleses de Porto Alegre, em junho de 2015, e no 10 Baile Senegalês, promovido pela Associação dos Senegaleses de Caxias do Sul, em agosto de 2015.

5 Disponível em: < http://www.acnur.org/t3/fileadmin/scripts/doc.php?file=t3\%2Ffileadmin\% 2FDoc umentos\%2Fportugues\%2FEstatisticas\%2FRefugio_no_Brasil_2010_2014>. 
instituição. Destes, 1841 eram homens, majoritariamente entre 21 e 35 anos (77\%). Os dados, sistematizados por pesquisa de Herédia e Pandolfi ${ }^{6}$, indicam, ainda, que 50,97\% dos migrantes senegaleses em Caxias do Sul são solteiros e 24,41\% possuem Ensino Fundamental incompleto e 15,09\%, Ensino Fundamental completo, enquanto 13,25\% concluíram o Ensino Médio.

Embora as informações refiram-se apenas a migrantes que passaram pela instituição de apoio em Caxias do Sul, são sinalizadoras de um perfil observado de modo mais amplo em outras cidades gaúchas: os migrantes senegaleses que escolhem o estado para viver são, principalmente, homens jovens em busca de oportunidades de trabalho. Em nossa pesquisa, sobretudo através dos procedimentos de observação participante e em entrevistas com migrantes senegaleses, confirma-se um perfil de sujeitos jovens, entre 20 e 30 anos, na maioria homens, e com grau de escolaridade variado. Todos os entrevistados eram falantes de wolof, um dos idiomas do Senegal, alguns também conheciam o árabe e já se comunicavam em português, com graus diferentes de conhecimento do idioma. Além disso, todos os migrantes com quem conversamos são muçulmanos e participam de encontros e atividades religiosas nas cidades estudadas. Construção civil e indústria de alimentos, sobretudo frigoríficos, são as principais fontes de trabalho para os migrantes, que também, diante do desemprego ou como alternativa para ampliar a renda, desenvolvem atividades como vendedores ambulantes nos centros urbanos pesquisados (Caxias do Sul, Passo Fundo e Porto Alegre).

Como discutido em outro trabalho ${ }^{7}$, as Tecnologias da Informação e Comunicação (TICs) vão assumir um caráter muito importante de articulação dos senegaleses. $\mathrm{O}$ uso de telefones celulares conectados à internet é uma constante na experiência destes sujeitos, tanto para se comunicar com a família no Senegal, quanto para a comunicação com outros que anteriormente migraram - além de servir para organizar as atividades de caráter associativo geridas pelos migrantes.

Diante deste cenário é que nos aproximamos de plataformas na internet criadas por migrantes senegaleses para auxílio nas reflexões acerca deste fenômeno migratório contemporâneo. Estas ambiências digitais são pensadas, em um primeiro momento, a partir do conceito de webdiáspora e inserem-se em um contexto mais amplo, de rearticulações do próprio processo comunicacional a partir das lógicas da comunicação em rede. A aproximação com os espaços criados e gerenciados por esses migrantes na rede social Facebook nos possibilita observar, conforme é intenção deste artigo, quais são os conteúdos e o que sinalizam as interações destes sujeitos que se associam (também) através das redes sociais na internet.

6 HeRÉDIA, Vania Beatriz Merlotti, PANDOLFI, Bruna. Migrações internacionais: o caso dos senegaleses em Caxias do Sul.

BRIGNOL, Liliane Dutra. Usos sociais das TICs em dinâmicas de transnacionalismo e comunicação migrante em rede: uma aproximação à diáspora senegalesa no sul do Brasil. 


\section{Comunicação em rede e webdiáspora}

Com a emergência de ambientes comunicacionais marcados pelo atravessamento de questões ligadas ao fenômeno migratório e a ampliação dos usos da internet por comunidades migrantes, é possível perceber uma profunda relação entre as migrações contemporâneas e as questões de acesso às tecnologias da informação e comunicação (TICS), gerando a necessidade de estudos sobre as dinâmicas de deslocamentos transnacionais num contexto da sociedade em rede, como propõem pensadores como Castells ${ }^{8}$ e Cardoso ${ }^{9}$.

Compartilhamos da ideia de que a ambiência organizada pela mediação das tecnologias e das mídias torna-se responsável por uma interconexão em escala antes inconcebível. Para Manuel Castells ${ }^{10}$, as redes configuram a lógica da sociedade informacional, ou seja, da organização social contemporânea que, para o sociólogo, se caracteriza pela geração, processamento e transmissão da informação como fonte fundamental de produtividade e poder, o que causaria uma transformação de nossa cultura material pelo mecanismo de um novo paradigma tecnológico, que se organiza em torno das $\mathrm{TICs}^{11}$.

A sociedade em rede, conforme entendemos nesta construção, pode ser compreendida como marcada, portanto, por mudanças na organização social, possibilitada pelo surgimento de tecnologias, aliada a mudanças de diferentes ordens, como econômicas e culturais. Nessa sociedade em rede, como também considera Cardoso ${ }^{12}$, a autonomia das escolhas de decisão está diretamente ligada com nossa capacidade de interação com as mídias, sem excluirmos, no entanto, a importância das interações face-a-face.

Neste contexto, a comunicação em rede pode ser entendida não como um modelo de comunicação que veio a substituir os anteriores, mas como um processo comunicacional marcado por características como digitalidade, interatividade, hipertextualidade, reticularidade e multimidialidade ${ }^{13}$, que reordena e articula os formatos e processos de comunicação como um todo. Como aborda Cardoso ${ }^{14}$, ela é moldada pela capacidade dos processos de globalização comunicacional mundiais, juntamente com articulação em rede massificada e a difusão de meios pessoais marcados pelo aparecimento da mediação em rede.

Tal proposição está relacionada com o conceito de autocomunicação massiva, abordado por Castells ${ }^{15}$, segundo o qual os usos da internet e das redes

CASTELLS, Manuel. A sociedade em rede.

9 CARDOSO, Gustavo. A mídia na sociedade em rede: filtros, vitrines, notícias.

10 Ibidem.

11 Ibidem.

12 Ibidem.

${ }^{13}$ SCOLARI, Carlos. Hipermediaciones: Elementos para una teoría de la comunicación digital interactiva.

${ }^{14}$ CARDOSO, op. cit.

${ }^{15}$ CASTELLS, Manuel. Redes de indignação e esperança. Movimentos sociais na era da internet. 
sem fio como plataformas da comunicação digital trouxeram uma mudança fundamental no domínio da comunicação. Como características, este processo baseia-se em redes horizontais de comunicação interativa, ao mesmo tempo em que é multimodal e permite a referência constante a um hipertexto global de informações. Desta forma, a autocomunicação massiva "fornece a plataforma tecnológica para a construção da autonomia do ator social, seja ele individual ou coletivo, em relação às instituições da sociedade" ${ }^{\prime \prime 16}$.

Martín-Barbero ${ }^{17}$ também destaca o lugar estratégico da comunicação na configuração de novos modelos de sociedade e na conformação de novas figuras de cidadania. Ao abordar o papel da mediação tecnológica no conhecimento da produção social, o autor trata de dois processos fundamentais de transformação em nossas sociedades: a revitalização das identidades e a revolução das tecnicidades. Ao nos aproximarmos do cenário da comunicação em rede, dialogamos com a percepção de Martín-Barbero ${ }^{18}$, para quem o lugar da cultura na sociedade muda com a mediação tecnológica, que "deixa de ser meramente instrumental para espessar-se, condensar-se e converter-se em estrutural: a tecnologia remete, hoje, não a alguns aparelhos, mas, sim, a novos modelos de percepção e de linguagem, a novas sensibilidades e escritas"19.

Inserido neste cenário mais amplo de transformações, o migrante, que antes tinha mais dificuldade para manter a comunicação com quem havia ficado longe, incorporou o uso das TICs como parte do processo migratório. O barateamento do custo das passagens aéreas, aliado à maior facilidade de acesso ao computador, à internet, ao telefone celular e a outras tecnologias ampliou a dimensão transnacional das migrações contemporâneas, tornando possível a experiência de estar aqui e lá ao mesmo tempo, senão fisicamente, ao menos através da mediação tecnológica.

Assim, usos sociais das TICs aparecem demandados pelas próprias experiências migratórias, implicando em questões de pertencimento, ao mesmo tempo em que atuam no modo como são construídas diferentes posições identitárias e modos de participação social para os migrantes. Em pesquisa anterior $^{20}$, com migrantes latino-americanos no Brasil e na Espanha, pontuamos dez dimensões de usos sociais da internet relacionados ao fenômeno migratório: como apoio na construção de projetos de migração, na manutenção de laços entre famílias e relações transnacionais, nos vínculos informativos com o país de nascimento, no consumo e na produção culturais, no aprendizado de

\footnotetext{
${ }^{16}$ Ibidem, p. 15.

17 MARTíN-BARBERO, Jesús. Tecnicidades, identidades, alteridades: mudanças e opacidades da comunicação no novo século.

18 Ibidem.

19 Ibidem, p. 54.

${ }^{20}$ BRIGNOL, Liliane Dutra. Migrações Transnacionais e Usos Sociais da Internet: Identidades e Cidadania na Diáspora Latino-Americana.
} 
idiomas, na obtenção de informações ligadas à cidadania jurídica, em usos de mídias de migração, como companhia e ócio, na participação política mediada tecnologicamente e na organização em entidades e movimentos associativos, atravessados pela condição migrante, latino-americana ou pelo sentido de pertença a uma identidade nacional ou étnica.

Estes sentidos para as apropriações sociais da internet por migrantes estão associados à reflexão do conceito de webdiáspora, que parte do reconhecimento da importância crescente das TICs, da internet e da web na experimentação dos deslocamentos transnacionais e fluxos interculturais na sociedade contemporânea. A diáspora, nos termos de Hall ${ }^{21}$, em uma ampliação da compreensão sobre as migrações contemporâneas, rompe com uma oposição rígida da diferença, e passa a ser entendida como ponto de partida para compreensão das relações identitárias. Estas relações identitárias ressignificadas pela experiência da diáspora passam a circular sentidos, permitir conexões, promover aproximações e tensionamentos também através de ambientes comunicacionais em rede, como sites, blogs, redes sociais online e outras plataformas de comunicação.

O conceito de webdiáspora ${ }^{22}$ está relacionado com a criação de ambientes comunicacionais marcados pela lógica do deslocamento e pela vivência em rede da própria diáspora. Incluem-se aí: múltiplos ambientes de comunicação na internet criados, mantidos, atualizados, usados por migrantes que passam a se apropriar da facilidade de acesso à esfera da produção na internet para seus próprios objetivos e demandas. Como webdiaspóricos são incluídos tanto páginas web, sites temáticos sobre migrações, quanto weblogs, sites pessoais, sites de ONGs e associações, perfis e páginas em redes sociais online, atravessados por questões relacionadas às vivências identitárias a partir de fluxos migratórios contemporâneos.

Em abordagem dedicada a estudar a relação entre internet e migrações, Scopsi ${ }^{23}$ discute sobre o papel das páginas web construídas por migrantes de unir os membros dos coletivos em diáspora, de modo a contribuir no reforço a um sentimento de pertença para grupos muitas vezes dispersos geograficamente. A autora propõe uma delimitação para o conceito, de modo que possa abarcar páginas web marcadas por um sentido de coesão e reivindicação identitária em torno da condição migrante.

Em revisão de literatura sobre o conceito de webdiáspora, Escudero ${ }^{24}$ destaca a contribuição da proposta de Scopsi ${ }^{25}$, assim como o debate de Mattelart ${ }^{26}$, para quem os estudos da webdiáspora devem observar o cuidado

\footnotetext{
${ }^{21}$ HALL, Stuart. Da diáspora: identidades e mediações culturais.

22 BRIGNOL, Migrações Transnacionais..., op. cit.

${ }^{23}$ SCOPSI, Claire. Les sites web diasporiques: um nouveau genre médiatique?

${ }^{24}$ ESCUDERO, Camila. A construção e organização da Webdiáspora.

${ }^{25}$ Ibidem.

${ }^{26}$ MATTELART, Tristan. Les diasporas à l'heure des technologies de l'information et de la communication: petit état des savoirs.
} 
de não idealizar estes espaços como essencialmente contra-hegemônicos, pois são também atravessados por relações de poder e sofrem constrangimentos econômicos e políticos. O autor chama a atenção para o fato de que "muitos estudos insistem em forjar um imaginário de que a internet promove a ideia de continuidade e manutenção da identidade dos povos dispersos (como o próprio termo diáspora chegou a descrever por um longo tempo), sem levar em conta as transformações naturais de processos interativos com outras realidades"27.

Peñaranda Cólera ${ }^{28}$ também se refere à experiência do "migrante conectado", entendido, com base em ampla recuperação do estado de arte de pesquisas sobre a reconfiguração das mobilidades migrantes em tempos de globalização e acesso ampliado às TICs, enquanto ator de uma cultura de vínculos.

La ruptura o suspensión de los valores, normas culturales e incluso de las raíces, siempre posible en el hecho migratorio, se convertiría hoy en circulación y mantenimiento del contacto. Es en este sentido que se podría hablar de la edad del migrante conectado, donde éste puede desarrollar redes, actividades, estilos de vida e ideologías que le permiten ligar su país de origen con el país de acogida ${ }^{29}$.

A conexão à comunicação em rede aparece, então, quase como condição inerente e configuradora do migrante contemporâneo. Sem desconsiderar situações de exclusão digital, em que, para muito migrantes, o acesso às tecnologias ainda se dá de maneira desigual, a relação entre usos sociais das TICs e migrações passa a ser importante para a construção de vínculos entre territórios, culturas e identidades.

A vivência das identidades é, portanto, central na construção da webdiáspora. Neste sentido, entendemos as identidades como articuladores de significados sociais. Nos termos de Castells: "Em um mundo de fluxos globais de riqueza, poder e imagens, a busca da identidade coletiva ou individual, atribuída ou construída, torna-se a fonte básica de significado social" ${ }^{\prime 30}$, pois, cada vez mais os indivíduos se organizam ao redor do que de fato são ou do que acreditam ser.

Podemos pensar que, além da identidade senegalesa (certamente também múltipla e diversa), o que os migrantes dessa nacionalidade constroem na interneté um espaço onde possam partilhar um mesmo sentido de pertença (com o Senegal) e parte de suas experiências migratórias (relacionadas à residência no Rio Grande do Sul, Brasil). Nesse aspecto, entendemos que as identidades se relacionam entre essas trocas. Assim, como pontua Gilroy, "las identidades procedentes de la nación podrían verse en competición con estructuras subnacionales (locales

\footnotetext{
${ }^{27}$ ESCUDERO, op. cit., p. 3.

${ }^{28}$ PEÑARANDA-CÓLERA, María Carmen. Migrando en tiempos de globalización: usos de tecnologías de la información y la comunicación en contextos migratorios transnacionales.

29 Ibidem, p. 2025.

${ }^{30}$ CASTELLS, A sociedade em rede..., op. cit., p. 41.
} 
y regionales) y supranacionales (diáspora) de pertenencia y parentesco ${ }^{31 "}$. As identidades, portanto, localizam-se no espaço-tempo simbólico com senso de lugar e pertencimento enraizados ${ }^{32}$. O uso das $\mathrm{TIC}^{\prime}$ 's cruza esse mesmo espaçotempo simbólico imbricado nas identidades. Pensar como o uso das TIC's e dos espaços nas redes sociais digitais afetam a experiência migrante é um desafio diante da relação que se estabelece entre tecnologia e sociedade.

\section{Para observar as redes sociais online de migrantes}

Para analisar ambientes comunicacionais na rede social online Facebook criados por migrantes senegaleses no Rio Grande do Sul, nos aproximamos da perspectiva da etnografia virtual, entendida enquanto uma adaptação do método etnográfico para o estudo no contexto virtual. Embora seja importante considerar o caráter contíguo e complementar entre as ambiências online e offline, o debate no contexto das Ciências Sociais e Humanas da noção de etnografia virtual é útil para se problematizar a prática etnográfica em contexto de mediação tecnológica.

De modo geral, com base em Hine ${ }^{33}$, pensamos a perspectiva etnográfica a partir do compromisso central de desenvolver uma compreensão profunda do social através da participação e da observação. A partir do entendimento da internet como cultura e como artefato cultural, a autora propõe o conceito de etnografia virtual como uma reavaliação dos fundamentos tradicionais da própria etnografia, que previa a presença prolongada do investigador em um espaço físico determinado. Hine ${ }^{34}$ defende a construção de uma etnografia virtual a partir das interações mediadas pelo computador, o que, em alguns casos, como desenvolvido nesta investigação, conforme as especificidades do problema de pesquisa, pode ser aliado ao deslocamento para além do ambiente da própria internet.

Acreditamos que a opção pela etnografia virtual implica na construção de um percurso metodológico artesanal, baseado no olhar atento das especificidades de cada contexto estudado, não sendo possível a adoção de um procedimento antes da própria entrada em campo. Para este exercício de observação exploratória, nos aproximamos da proposta de Johnson ${ }^{35}$ sobre os estudos situados nos cenários sociotécnicos, os mesmos que exigem "estratégias metodológicas situadas, flexíveis e práticas condizentes com as necessidades de situações particulares ${ }^{36 \prime}$, principalmente na ambiência da internet.

${ }^{31}$ GILROY, Paul. Estudios culturales y comunicación: análisis, producción y consumo cultural de las políticas de identidad y el posmodernismo, p. 81.

32 HALL, Stuart. A identidade cultural na pós-modernidade.

${ }^{33}$ HINE, Christine. Etnografía virtual.

${ }^{34}$ Ibidem.

${ }^{35}$ JOHNSON, Telma. Pesquisa social mediada por computador: questões, metodologia e técnicas qualitativas.

36 Ibidem, p. 61. 


\section{Senegaleses no RS e no Facebook}

A seguir, trazemos elementos da análise de quatro páginas criadas e geridas por migrantes senegaleses que residem em três cidades gaúchas distintas: Caxias do Sul, Passo Fundo e Porto Alegre, representantivas quanto à presença migratória deste coletivo. Também é analisado um perfil (ao contrário das outras três, que estão no formato página disponibilizadas no Facebook) que aglutina senegaleses em todo o Rio Grande do Sul.

\section{1) Associação dos Senegaleses em Caxias do Sul ${ }^{37}$}

Página oficial criada na rede social Facebook e descrita como "organização". Ao todo, 1417 pessoas curtem a página (até o final da análise para este artigo, em fevereiro de 2016). Os idiomas utilizados para postar na página oscilam entre francês, inglês, português e idiomas locais de diferentes regiões do Senegal. Já na apresentação da página, há a descrição do presidente e vice-presidente da Associação (Abdou Lahat Ndiaye, conhecido como Bili, e Cheikh Mbacke Gueye, respectivamente).

A última postagem da página (no dia 16 de dezembro de 2015) é uma chamada para a III Marcha dos Migrantes de Caxias do Sul, realizada no mês de dezembro. Destaca-se, ainda, um link do site Helping Hand, site para auxílio a migrantes e disponível em diversos idiomas. Outra postagem trata do falecimento de Cheye Seye, senegalês que integrava a Associação, em março de 2015, na cidade de Novo Hamburgo (RS). A postagem solicitava dos integrantes da Associação uma quantia de $\mathrm{R}$ \$ 50,00 para ajudar a enviar o corpo de volta ao Senegal, para os devidos ritos funerários, o que demonstra uma apropriação da rede social online para mobilização e solidariedade entre os migrantes. Em postagens anteriores (em francês), a Associação comunicou o falecimento de Seye.

Na página, há a disponibilização de alguns prints de jornais locais com matérias e editoriais a respeito de pautas dos migrantes senegaleses. Uma das postagens é uma notícia a respeito da segunda celebração da Festa de Touba (celebração religiosa islâmica), realizada em Caxias do Sul pela Associação (Figura 1). Ao final de 2014, durante a celebração religiosa, algumas matérias foram publicadas pelos jornais locais e as mesmas foram compartilhadas pelos gerenciadores da página da Associação. O editorial do Jornal O Pioneiro (do Grupo RBS, localizado em Caxias do Sul) traz em seu título a frase "Os senegaleses estão em casa". O texto trata sobre a realização da festa e a forma como a mesma já teria sido incorporada pela comunidade local.

\footnotetext{
${ }^{37}$ Cf. <https://www.facebook.com/Associação-dos-Senegaleses-em-Caxias-do-Sul-1450366275195921>.
} 
FIGURA 1 - Print de postagem da página Associação dos Senegaleses em Caxias do Sul com reportagem de jornal local Folha de Caxias

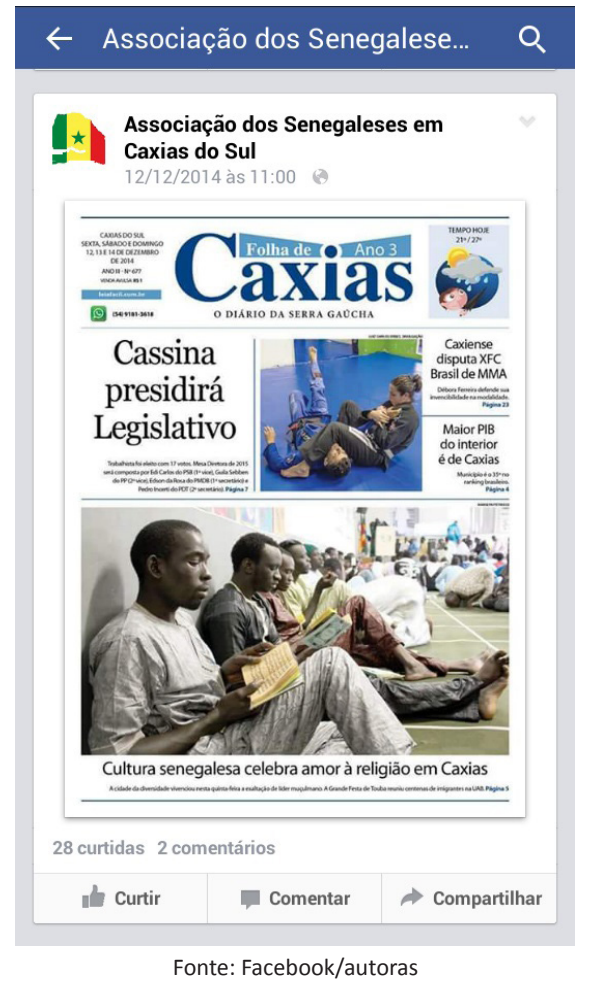

Em outra postagem, publicada como foto de capa da página, é destacado um encontro realizado na Câmara de Vereadores de Caxias do Sul, e a imagem traz representantes senegaleses ao lado de vereadores do município. Outro elemento interessante postado na página é o discurso de Serigne Mame Mor, realizado em um evento promovido em março de 2015 pela Associação. Em um momento do discurso (traduzido para o português por outro membro da Associação), Serigne Mame Mor diz: "A solidariedade e o humanismo são valores importantes num planeta em que as próprias pessoas criaram as diferenças". Toda a tônica do discurso é de vertente religiosa e prega pela aceitação e respeito aos diferentes povos, além de exaltar a forma como a comunidade senegalesa está instalada e recebida pela comunidade gaúcha em Caxias do Sul.

\section{2) Senegaleses Noriogrande 38}

Neste caso, não se trata de uma página - nos termos oferecidos pelo Facebook - mas de um perfil de usuário. O perfil possui outras possibilidades

${ }^{38}$ Cf. <https://www.facebook.com/profile.php?id=100007011017048>. 
e relação dentro da rede social. O perfil, que leva o nome de Senegaleses Noriogrande, se apresenta como residente em Passo Fundo (RS). Também afirma estudar na instituição de ensino Universidade de Passo Fundo (UPF). Muitos amigos do perfil são senegaleses com seus perfis no Facebook. Nas preferências culturais, o perfil apresenta artistas senegaleses e outros elementos da cultura nacional. Como exemplo de postagem, no dia 18 de junho de 2015, publicam informação sobre o início do Ramadah, mês sagrado para a religião islâmica, desejando "muita felicidade para todos os muçolmono". A postagem termina com um texto escrito no idioma wolof.

FIGURA 2 - Print de postagem do perfil Senegaleses Noriogrande

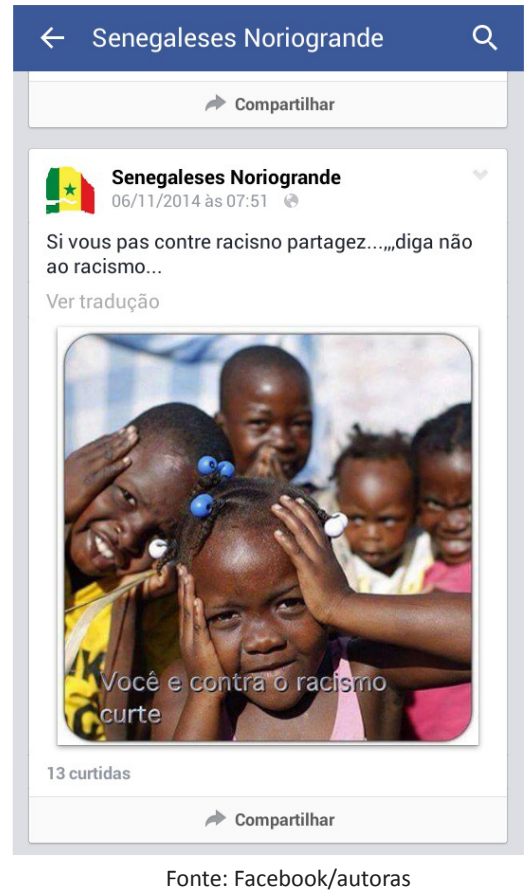

Uma das postagens do grupo (Figura 2), de novembro de 2014, traz uma imagem com crianças negras e a escrita, do próprio perfil, "Si vous pás contre racisno partagez... diga não ao racismo...". A opção por disponibilizar textos, vídeos e imagens que possam ser compartilhadas por usuários da rede social Facebook é uma estratégia utilizada por inúmeras páginas (comerciais ou comunitárias) e perfis nesse espaço. O compartilhamento (ferramenta do Facebook) é, imageticamente, a partilha de noções, interesses e compreensões semelhantes entre usuários da rede. O perfil também traz muitas imagens de festas e celebrações, além de representações do Senegal e de povos africanos. O 
perfil também interage com a página da Associação dos Senegaleses em Caxias do Sul, compartilhando imagens disponibilizadas pela página.

\section{3) Associação dos Senegaleses de Porto Alegre ${ }^{39}$}

Ao todo, 715 pessoas curtem a página, que se define enquanto organização comunitária. Como descrição da página aparece a informação: "Esta página (ADSPOA) tem por objetivo reunir os senegaleses para lutarmos juntos e revelar as dificuldades que estamos vivendo na sociedade". Mais do que o objetivo da fanpage, trata-se também do objetivo da própria associação, presidida pelo senegalês Mor NDiaye. A página também traz vídeos de reuniões da Associação, funcionando como um espaço digital para informações a respeito das ações da entidade. Nesse caso, assim como a página da Associação dos Senegaleses em Caxias do Sul, é um braço midiático de uma rede que existe presencialmente: os integrantes realizam reuniões periódicas e alguns vídeos, fotos e decisões são postados no Facebook.

Uma das postagens analisadas (do dia 13 de junho de 2015) traz uma reportagem produzida pelo Jornal do Almoço (da RBS TV, afiliada da Rede Globo de Televisão) intitulada "Imigrantes contam o que vieram buscar no Brasil". Em meio a palavras do idioma wolof, a postagem traz o termo "représenter", em referência à representação dos migrantes na matéria. Nos comentários, evidencia-se a sensação positiva diante da maneira como os próprios senegaleses foram representados na matéria. O espaço é bastante utilizado para divulgar e lembrar as datas e pautas das reuniões da Associação, além do compartilhamento posterior de atividades realizadas, com imagens de celebrações e encontros. Na capa da página (Figura 3), uma montagem traz as bandeiras do Brasil e Senegal unidas por duas mãos dadas, evidenciando a noção de solidariedade e receptividade entre as nações aos olhos dos gerenciadores da página.

Ao longo do período de observação, o que inclui também a participação em atividades promovidas presencialmente pelo grupo, percebemos que a associação vai assumindo um caráter organizativo e reivindicatório importante no contexto da migração senegalesa no RS. No Facebook, isto é indicado, por exemplo, em postagens sobre a assinatura de convênio para abertura de centro de acolhimento a migrantes em Porto Alegre, uma das bandeiras de luta da associação. Há também postagens que se referem a matérias na mídia massiva sobre casos de violência contra senegaleses, sempre seguidas de mensagens críticas e de alerta sobre os direitos dos sujeitos migrantes. Além disto, a página repercute ações religiosas promovidas, como a grande festa Magal Touba, celebração em homenagem a Cheikh Ahmadou Bamba, líder islâmico do Senegal,

${ }^{39}$ Cf. <https://www.facebook.com/adspoa/>. 
comemorada mundialmente, e que reuniu, no dia $1^{10}$ de novembro de 2015 , mais de 500 migrantes na capital gaúcha.

\section{FIGURA 3 - Print da capa da página da Associação dos Senegaleses de Porto Alegre}

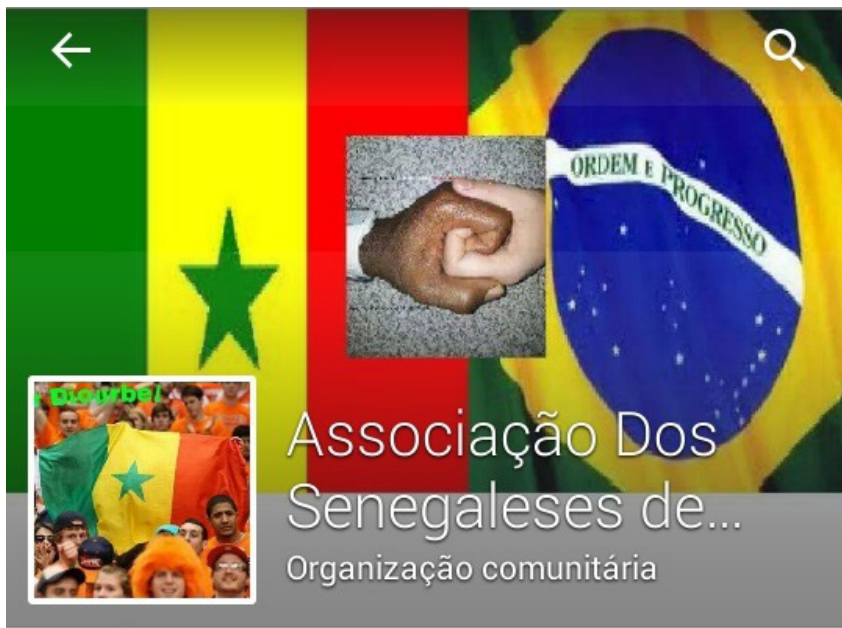

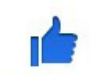

Curtiu

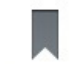

Salvar

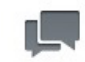

Mensagem

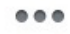

Mais

Fonte: Facebook/autoras

\section{4) Immigrante Senegalais Caxias do Sul ${ }^{40}$}

Eram 780 pessoas curtidas até a última checagem para a análise, mas a página não se encontra mais ativa no Facebook. Ao contrário da página da Associação dos Senegaleses de Caxias do Sul, apresentava um formato de encontro virtual de seus integrantes, não sendo uma ferramenta para gestão da comunicação de um grupo criado no contexto offline, mas uma ambiência de interação desenvolvida especialmente para a rede social Facebook. Portanto, não possuía uma estrutura organizacional física e presencial, sendo mais um espaço na web para encontro e trocas entre os senegaleses que vivem experiências migratórias semelhantes. Com atualização mais restrita, trazia imagens da cultura senegalesa (incluindo esportes, roupas e danças), além de imagens de Dakar (capital do país). Observamos uma preocupação com imagens críticas ao racismo e a favor da igualdade. A página também fomentava informações a respeito da seleção de futebol do Senegal (Figura 4), apelidada de "lions" ("leões", em francês).

\footnotetext{
40 Página não mais ativa no Facebook.
} 
FIGURA 4 - Print com a imagem da postagem sobre a seleção senegalesa (Les Lions)

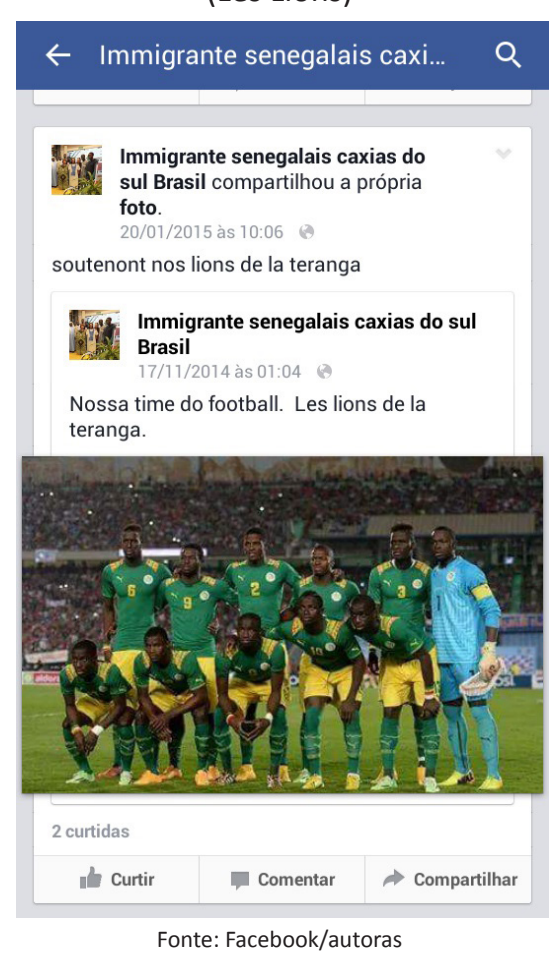

\section{Considerações finais}

Algo que se repete nos quatro ambientes comunicacionais analisados (páginas e perfil criadas e gerenciadas por migrantes senegaleses que residem no Rio Grande do Sul) é a valorização da cultura senegalesa e a presença de elementos que caracterizam o Senegal: referências à bandeira nacional, uso do idioma francês e idiomas locais nas publicações, fotos que representam ou os senegaleses residentes no Estado ou imagens do Senegal e de artistas e lideranças locais. A demonstração da valoração da cultura senegalesa é importante para que compreendamos o quanto a ligação com o país de nascimento é necessária para a identidade migrante desses sujeitos e para a sua experiência em território brasileiro.

O elemento mais evidente é o fato de as páginas serem utilizadas conforme os objetivos do grupo. Em sua maioria, a necessidade parece ser a de informar locais de trabalho, questões referentes à documentação para migrantes no Brasil, avisos de festas, celebrações e encontros, bem como postagens de fotos. A opção por postagens no idioma wolof salienta o objetivo da página: mais do que externar "internacionalmente" ações e questões referentes aos senegaleses 
em determinada região, a função das páginas é de auxiliar os migrantes em sua experiência migratória, emitindo comunicados, avisos e oportunidades diversas que possam ser compreendidos pelos falantes daquele idioma. Ainda assim, em algumas páginas, há a preocupação da tradução de algumas postagens para o francês e para o português. A participação de brasileiros (em comentários nas postagens divulgadas pela página) mostra a aproximação em curso entre brasileiros e senegaleses. As postagens em português (ou traduzidas para esse idioma) evidenciam algumas trocas ocorridas, sobretudo no caso de convites para atividades associativas, de caráter cultural ou político.

Uma característica presente nos quatro espaços é, também, a valorização da religião islâmica. Com $90 \%$ da sua população adepta ao islamismo (mais especificamente, à vertente do mouridismo ${ }^{41}$ ), o Senegal é um país bastante religioso e suas práticas permanecem na experiência migratória dos senegaleses no Rio Grande do Sul. Imagens de cerimônias, convites para celebrações, orações, representação de líderes religiosos e outros tipos de divulgação dos preceitos da religião islâmica estão presentes nas quatro páginas observadas. A religião fornece um ponto de ligação e solidariedade entre os migrantes, sendo extremamente importante na organização articulada nos locais para os quais migram, como já observamos no associativismo migrante nas cidades gaúchas estudadas.

Por mais que as atualizações não sigam um ritmo frequente nas quatro páginas (não sendo geridas para atualizações diárias e nem apresentando um padrão de postagem organizada), elas ainda representam boa parte daquilo que os senegaleses buscam expressar ou organizar em sua experiência migratória no Brasil. Através de outras observações empíricas, percebemos que muitos migrantes senegaleses utilizam com muita frequência telefones celulares com acesso à internet e redes sociais presentes nesses dispositivos (não apenas o Facebook, como também outras plataformas gratuitas para troca de mensagens e diversos modos de interação).

Nestes usos do telefone celular e da internet, percebemos mais diretamente as tecnologias assumindo um papel preponderante na manutenção de laços entre famílias e nas relações transnacionais, assim como no apoio à construção de projetos de migração. Os senegaleses fazem referência, em seus relatos, aos contatos com familiares e amigos através de aplicativos para troca instantânea de mensagens (como Whatsapp, Viber e Imo), por exemplo. Do mesmo modo, há depoimentos que falam do contato anterior feito entre senegaleses no seu país de nascimento com sujeitos que já se encontravam no Brasil. A referência inicial, muitas vezes, mesmo para aqueles que não possuem familiares e amigos

${ }^{41}$ Ordem mouride do islamismo, fundada pelo senegalês Cheikh Amadou Bamba em 1883. Tem sua sede religiosa localizada na cidade de Touba (Senegal), para onde milhares de devotos se encaminham anualmente em celebração religiosa. Estima-se que os seguidores do mouridismo ultrapassem o número de três milhões em todo o mundo. 
próximos no país, é o número de um telefone celular de algum conhecido que já migrou. Esta perspectiva para apropriação das TICs na experiência migratória senegalesa no sul do Brasil foi abordada em outro trabalho ${ }^{42}$. No caso das páginas no Facebook, identificamos, predominantemente, uma prática de comunicação que é complementar a esta, servindo como integração de grupos migrantes organizados, a exemplo das associações, assim como espaço de visibilidade de temas relacionados à experiência migratória e de construção de espaços de integração e participação social.

Assim, também fica bastante saliente a demonstração de empatia e solidariedade dos migrantes em relação à receptividade que recebem do Brasil, com a publicação de reportagens de telejornais e jornais impressos locais. Esta constatação não exclui a referência a questões de conflitos ou dificuldades, evidenciadas sob o caráter de denúncia ao preconceito explícito ou velado sofrido pelos migrantes, o que pode ser inferido pela divulgação de fotos e de campanhas contra o racismo, assim como em denúncias contra situações de violência ou abuso aos direitos migrantes.

No geral, os usos que são feitos das redes sociais online e de outros espaços de troca e dinâmicas culturais e comunicacionais por migrantes senegaleses indicam o caráter dinâmico e complexo de uma diáspora que se constrói a partir de experiências transnacionais atravessadas pela mediação tecnológica. A webdiáspora surge enquanto possibilidade de experimentação e de afirmação identitária, assim como lugar de encontro de uma migração que se organiza em termos de grupos que disputam políticas de posição e reconhecimento no Brasil, como bem sinalizam as associações migrantes analisadas. Entre dinâmicas de aproximação e valorização cultural, religiosa e de afirmação política, as páginas observadas indicam abertura para possibilidade de interlocução entre migrantes de outras nacionalidades, brasileiros e senegaleses, em uma ambiência de experimentação identitária circunscrita pelas possibilidades técnicas da própria plataforma em que é proposta, a rede social online Facebook.

Esta análise traz algumas pistas sobre as trocas comunicacionais e os usos que os próprios migrantes fazem de seus perfis na rede social Facebook. Estudos sobre comunicação em rede e migrações transnacionais levantam questões importantes a serem enfrentadas para a compreensão dos novos contornos dos fluxos migratórios no mundo. Neste contexto de consolidação de redes migratórias e da organização de entidades de caráter associativo, as Tecnologias da Informação e Comunicação, a exemplo do que analisamos nas páginas da rede social online Facebook, assumem um caráter muito importante de articulação dos migrantes. É o que buscamos compreender na pesquisa ainda em desenvolvimento, na qual aliamos, além do olhar sobre as próprias plataformas

${ }^{42}$ BRIGNOL, Usos sociais das TICs..., op. cit. 
de comunicação online, os relatos dos sujeitos migrantes, suas trajetórias de migração e lógicas de comunicação em rede, em uma dinâmica construída entre deslocamentos, pertenças identitárias e usos das TICs.

\section{Referências}

BRIGNOL, Liliane Dutra. Migrações Transnacionais e Usos Sociais da Internet: Identidades e Cidadania na Diáspora Latino-Americana. São Leopoldo: Unisinos, 2010. Tese de Doutorado em Ciências da Comunicação, Programa de Pós-Graduação em Ciências da Comunicação, Universidade do Vale do Rio dos Sinos, 2010.

BRIGNOL, Liliane Dutra. Usos sociais das TICs em dinâmicas de transnacionalismo e comunicação migrante em rede: uma aproximação à diáspora senegalesa no sul do Brasil. Comunicação, Mídia e Consumo, v. 12, n. 35, set./dez. 2015, p. 89-109. Disponível em: < http://revistacmc.espm.br/index.php/revistacmc/article/ view/1099/502>. Acesso em: 10.03.2016.

BRIGNOL, Liliane; COGO, Denise. Redes sociais e os estudos de recepção na internet. In Associação Nacional dos Programas de Pós-Graduação em Comunicação. XIX Encontro da Compós. Rio de Janeiro, 2010.

CARDOSO, Gustavo. A mídia na sociedade em rede: filtros, vitrines, notícias. Rio de Janeiro: FGV, 2007.

CASTELLS, Manuel. A sociedade em rede. Rio de Janeiro: Paz e Terra, 2000.

CASTELLS, Manuel. Redes de indignação e esperança. Movimentos sociais na era da internet. Rio de Janeiro: Zahar, 2013.

ESCUDERO, Camila. A construção e organização da Webdiáspora. Anais do $3^{\circ}$ Encontro Regional Sudeste de História da Mídia - Mídia e Memórias do Autoritarismo. Rio de Janeiro: ECO-UFRJ, 14 e 15 de abril de 2014. Disponível em: < http://www.ufrgs. br/alcar/encontros-nacionais-1/encontros-regionais/sudeste/3o-encontro-2014/gt7-2013-historia-da-midia-alternativa > . Acesso em: 12.07.2015.

GILROY, Paul. Estudios culturales y comunicación: análisis, producción y consumo cultural de las políticas de identidad y el posmodernismo. Barcelona: Paidós, 1998, p. 63-83.

HALL, Stuart. A identidade cultural na pós-modernidade. Rio de Janeiro: DP\&A Editoria, 2006.

HALL, Stuart. Identidade cultural e diáspora. Revista do Patrimônio Histórico e Artístico Nacional, n. 24, 1996, p. 68-76.

HALL, Stuart. Da diáspora: identidades e mediações culturais. Belo Horizonte/Brasília: Editora UFMG/UNESCO, 2003.

HERÉDIA, Vania Beatriz Merlotti; PANDOLFI, Bruna. Migrações internacionais: o caso dos senegaleses em Caxias do Sul. In HERÉDIA, Vania Beatriz Merlotti (org.). Migrações internacionais: o caso dos senegaleses no Sul do Brasil. Caxias do Sul: Belas Letras, 2015.

HINE, Christine. Etnografía virtual. Barcelona: Editorial UOC, 2004.

JOHNSON, Telma. Pesquisa social mediada por computador: questões, metodologia e técnicas qualitativas. Rio de Janeiro: E-papers, 2010. 
MARTíN-BARBERO, Jesús. Tecnicidades, identidades, alteridades: mudanças e opacidades da comunicação no novo século. In MORAES, Denis (org.). Sociedade midiatizada. Rio de Janeiro: Mauad, 2006.

MATTELART, Tristan. Les diasporas à l'heure des technologies de l'information et de la communication: petit état des savoirs. TIC \& Société, v. 3, n. 1-2, 2009. Disponível em: <http://ticetsociete.revues.org/640>. Acesso em: 10.04.2015.

PEÑARANDA-CÓLERA, María Carmen. Migrando en tiempos de globalización: usos de tecnologías de la información y la comunicación en contextos migratorios transnacionales. In GARCÍA CASTAÑO, Francisco Javier; KRESSOVA, Nina (coords.). Actas del I Congreso Internacional sobre Migraciones en Andalucía. Granada: Instituto de Migraciones, 2011, p. 2023-2032.

RECUERO, Raquel. Redes sociais na internet. 2aa edição, Porto Alegre: Sulina, 2011.

SCOLARI, Carlos. Hipermediaciones: Elementos para una teoría de la comunicación digital interactiva. Barcelona: Gedisa, 2008.

SCOPSI, Claire. Les sites web diasporiques: un nouveau genre médiatique? TIC \& Société, v. 3, n. 1-2. 2009. Disponível em: < http://ticetsociete.revues.org/640>. Acesso em: 10.04.2015.

\section{Abstract \\ Migration and social uses of facebook: An Approach to Senegalese Web Diaspora in Rio Grande do Sul}

This article begins with a discussion about relations between network communication and transnational migration. The concept of webdiaspora is also presented. In the second part of the paper, four Facebook pages of Senegalese migrants living in Rio Grande do Sul are analyzed. In this work paper, Facebook is understood as part of migration dynamics, like a communication environment of identity affirmation. Likewise, Facebook is considered to be a meeting place of a diaspora that is organized in terms of associations for recognition policies in Brazil. The text is part of a communication research about TICS and migration dynamics between Senegal and Rio Grande do Sul.

Keywords: network communication, migration, webdiaspora, Senegal, Facebook.

Recebido para publicação em 19.02.2016

Aceito para publicação em 21.03.2016

Received for publication in February 19 192016

Accepted for publication in March 215t, 2016

ISSN impresso 1980-8585

ISSN eletrônico 2237-9843

http://dx.doi.org/10.1590/1980-85852503880004607 